\title{
Occipital Bone Cyst Causing Lower Cranial Nerve Palsies
}

\author{
*M. BANNA, W. G. BRADLEY, R. M. KALBAG and B. E. TOMLINSON
}

SUMMARY: A 20-year-old girl presented with neck and occipital pain for six weeks, which was found to be due to a unicameral bone cyst of the left occipital condylar region.

Although there have been very few reports of simple bone cysts in bones than the long tubular bones, it appears that the present case is probably the first report of such a lesion occurring in the skull.

RÉSUMÉ: Une jeune fille de 20 ans s'est présentée avec des douleurs occipitales et dans le cou depuis 6 semaines qui étaient dues à un kyste osseux unicaméral dans la région condylaire occipitale gauche.

Bien qu'il n'y ait eu que très peu de cas signalés de simples kystes osseux ailleurs que dans les os longs tubulaires, le présent cas est probablement le premier rapporté avec une telle lésion se présentant au niveau du crâne.

From the Regional Neurological Center, Newcastle-upon-Tyne University Hospitals, Newcastle-upon-Tyne, England.

*Present Address: Radiology Department, McMaster University, Hamilton 16, Ontario, Canada.

Reprint requests to Dr. M. Banna, Department of Radiology, McMaster Medical Center, 1200 Main St. W., Hamilton 16, Ontario, Canada.

\section{INTRODUCTION}

The causes of a benign osteolytic lesion in the skull are well known and include eosinophilic granuloma (histiocytosis X), cavernous hemangioma, epidermoid cyst, fibrous dysplasia, leoptomeningeal cyst and occasionally intracranial meningioma. Much rarer lesions include: giant cell tumors (Tudway, 1959; Jackson and Milton, 1960), osteoid osteoma (Munk, Peyser and Gellei, 1960), intraosseous lipoma (Dahlin, 1967), aneurysmal bone cyst (Odeku and Mainwaring, 1967; Burns-Cox and Higgins, 1969) and neurofibromatosis (Joffe, 1965). Some of these lesions may be associated with bone expansion and sclerosis.

The present paper is concerned with the description of another tumor which hitherto has not been known to occur in the skull.

\section{L. (N. 44515)}

\section{CASE HISTORY}

Six weeks before admission this 20-year-old girl gradually developed occipital headaches and pains at the back of the neck. These were aching in character, constant night and day, and gradually worsened. The pain radiated over the vertex to the frontal region, and down the neck to the shoulders, particularly on the left side. Movement of the head and neck made the pain worse. She felt well, but was increasingly distressed by the pain which began to keep her awake at night. There was neither fever or deafness. Her family doctor saw her on several occasions in the six weeks prior to admission, and the only abnormality found was a slightly pink left ear drum. She had two, five-day courses of antibiotics without effect upon the pain.

On examination, her head and neck were deviated to the right, and all attempts at active or passive neck movement were resisted because of pain. The left tympanic membrane appeared slightly dull and pink, and there was a very slight degree of conductive deafness on the left. On the first examination the tongue deviated slightly to the left. Over the next few days the occipital pain and neck stiffness improved considerably, and the deviation of the tongue disappeared. About a week later the pain in the neck recurred, together with evidence of mild paresis of the left $7 \mathrm{th}$, 9th, 10 th and 12 th, cranial nerves.

\section{Investigation}

Hemoglobin $13.6 \mathrm{G} / 100 \mathrm{ml}$; white blood cell count (W.C.C.) $5,500 / \mathrm{cu} \mathrm{mm}$.; erythrocyte sedimentation rate (E.S.R.) $7 \mathrm{~mm}$ in one hour. Blood urea and electrolytes were normal. Cerebrospinal fluid (C.S.F.) protein was $40 \mathrm{mg} / 100 \mathrm{ml}$. : no pleocytosis. Blood serology for syphilis was negative. Chest and cervical spine $x$-ray were normal. Initially the skull $x$-rays were difficult to obtain because of neck pain and restriction of movement, and no abnormality was detected. Because a lesion in the craniocervical region was initially suspected, a prone and supine myelogram was performed, revealing no abnormality. However, during myelography an osteolytic area in the mastoid part of the temporal bone was discovered. Further radiographs including tomograms revealed extension of the bone destruction to the jugular foramen, the hypoglossal canal, the antero-lateral margin of the foramen magnum, and the occipital condyle (Figure 1). The margin of this osteolytic area was in part sclerosed, but no bone expansion was present and the mastoid air cells were fully pneumatised. A skeletal survey was performed and failed to show any other lesion.

E.N.T. consultation (Mr. Ivor Frew): The appearance of the left drum was suggestive of secretory otitis media, and under general anaesthesia myringotomy produced more than $5 \mathrm{ml}$ of straw coloured fluid which welled out of the middle ear. The fluid was sterile, contained no cells and had a protein concentration of $5.3 \mathrm{~g} / 100 \mathrm{ml}$.

\section{Operation}

A left sub-occipital exploration revealed markedly thin bone behind the 
left mastoid process with a cyst lying between the inner and outer tables of the squamous occipital bone. The cyst lay in the region of the left mastoid process and occipital condyle, and had eroded through into the middle ear cavity and to the dura of the posterior fossa in the region of the hypoglossal canal. The cavity of the cyst did not communicate with any of these adjacent structures. The cyst fluid was yellow, and similar to that obtained from the middle ear at myringotomy. The interior was lined by smooth membrane, and was divided into two intercommunicating shallow loculi by a bony partition approximately in the position of the occipital condyle. The interior of the cyst was curetted and treated with absolute alcohol. The lining of the cyst did not bleed excessively when cut.

\section{Histology}

The cyst wall consisted of welldifferentiated fibrous tissue in which there was a thin layer of bone, and some foci of calcification (Figure 2). Osteoclastic activity was prominent on the cyst-side of the bone, and in places the cyst had eroded through the bone. There were heavy deposits of hemosiderin in the fibrous wall of the cyst, which was not particularly vascular. The appearances were those of a simple bone cyst.

Following the operation she was placed in a modified Minerva collar, which she wore for eight weeks. The occipital headaches were relieved by the operation. Three months after the operation her head and neck movements were normal, and tomograms of the base of the skull showed early formation of new bone in the eroded area (Figure 3). There was mild weakness and wasting of the left side of the tongue.

Figure 1-Three different views to show the extension of bone destruction. (A) Oblique lateral radiograph showing destruction in the mastoid portion of the temporal bone and adjacent squamous part of the occipital bone with marginal sclerosis (arrow). (B) Submento-vertical view showing involvement of the jugular foramen, the hypoglossal canal and the anterolateral margin of the foramen magnum. (C) Coronal plane tomogram showing destruction of the occipital condyle (asterisk) and the region of foramen jugulare.

\section{DISCUSSION}

This patient presented with six weeks of occipital headache, leading to restriction of movement of the neck and mild paresis of the left $7 \mathrm{th}$, 9 th, 10th and 12th cranial nerves
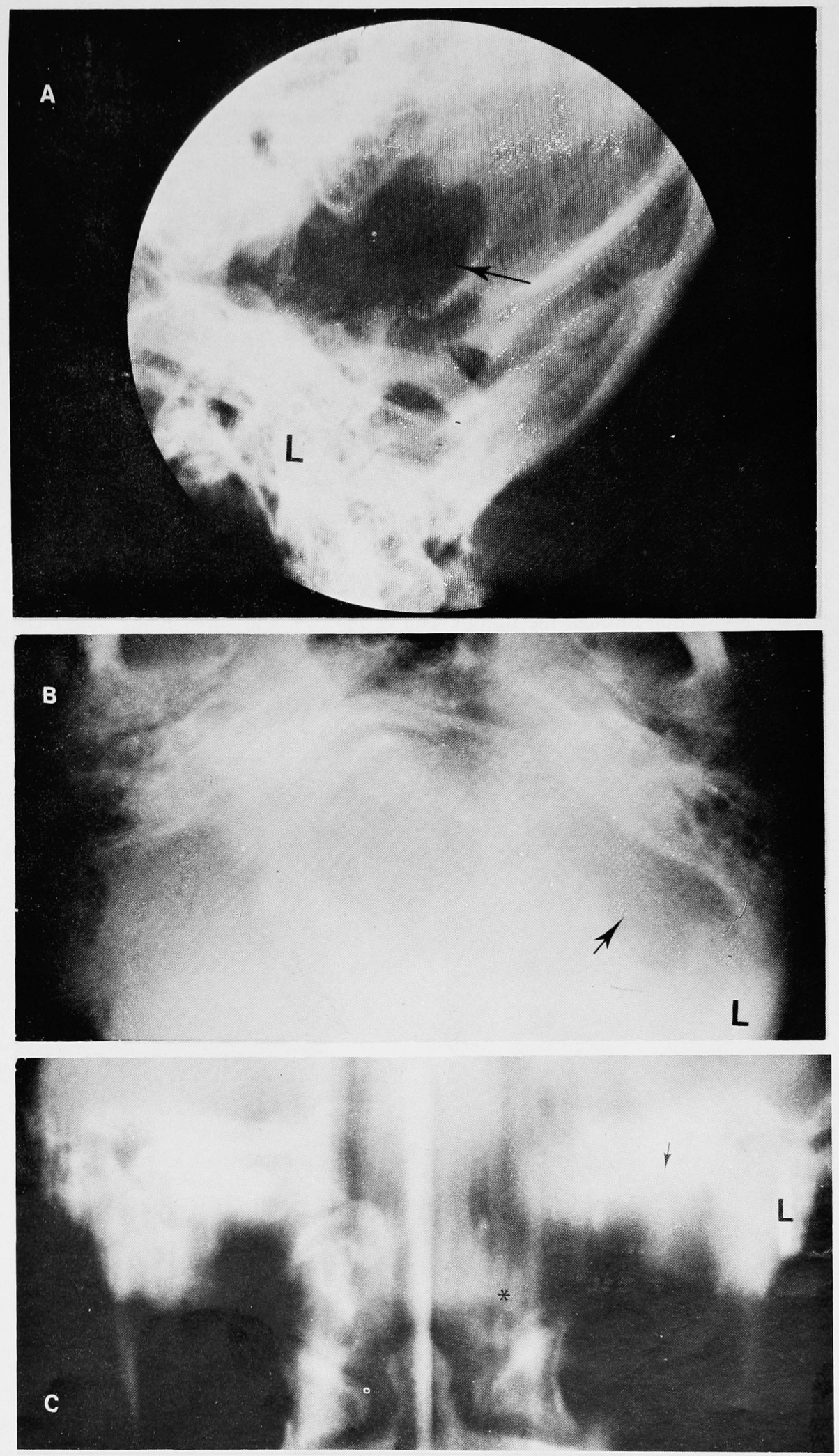
together with mild conductive deafness on the left. The radiological and pathological features of the cyst, however, indicated that the condition had been present for many months, probably years. It is pos-

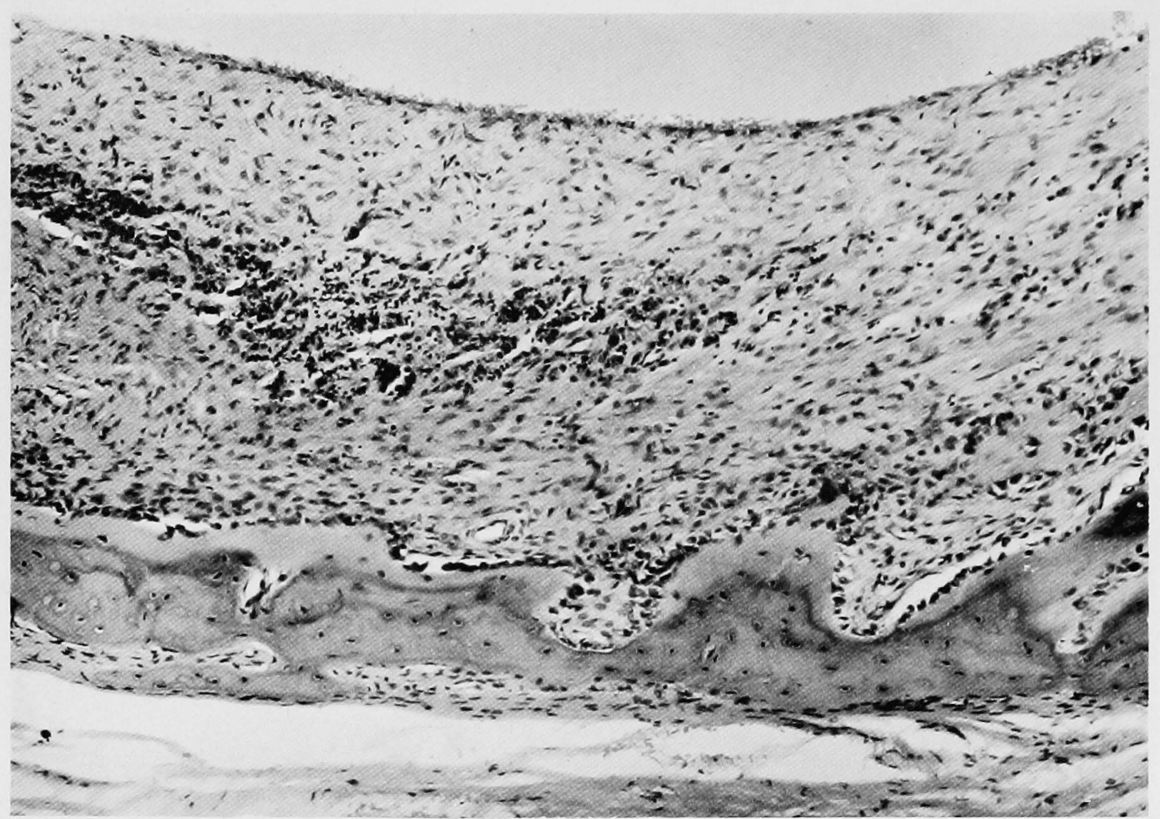

Figure 2-Section through the fibrous wall of the cyst and surrounding bone. The fibrous cyst wall is sparsely vascular but hematin-laden macrophages and some fresh hemorrhages are present. (H. and E. X150).
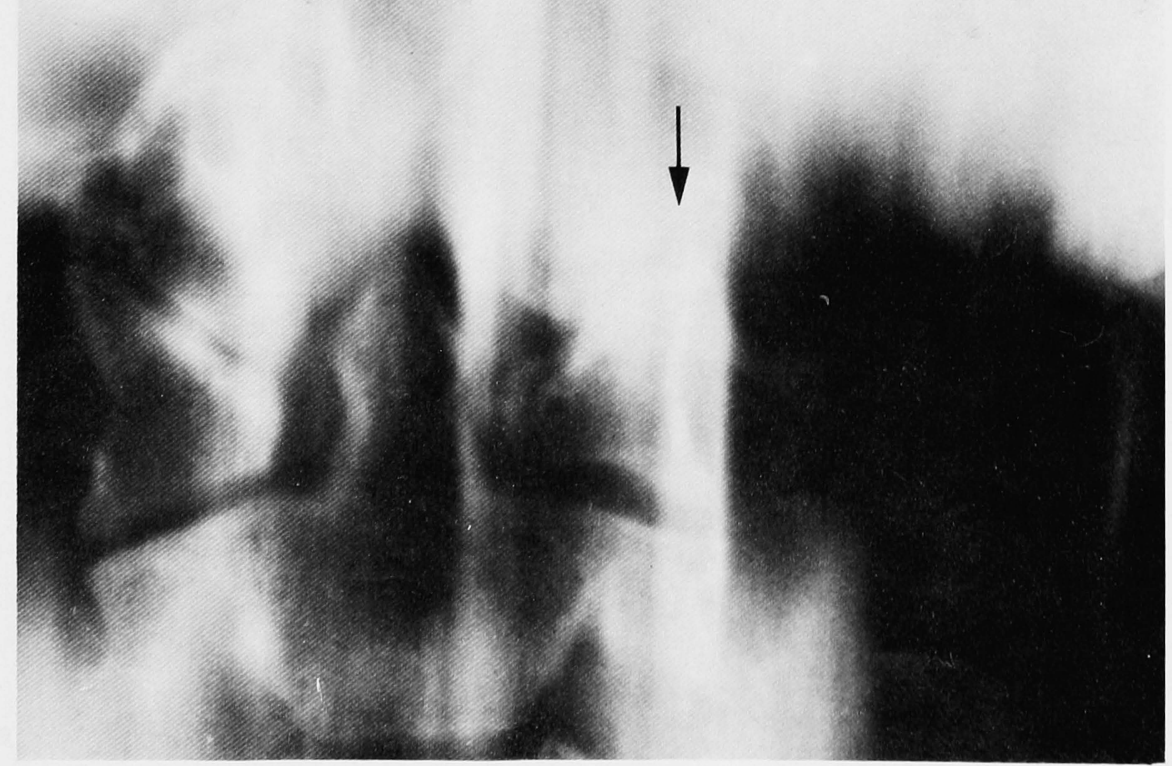

Figure 3-Tomographic cut in the coronal plane comparable to Figure 1(C) and taken about three months later showing early new bone formation in the occipital condyle (arrow). sible that the cyst only presented when it eroded the jugular foramen and the hypoglossal canal causing 9th, 10th and 12th cranial nerve paresis. It had also invaded the middle ear cavity producing conductive deafness and facial nerve paresis. The fluid obtained at myringotomy was the same proteinacious yellow fluid that was seen within the cyst at the time of the occipital exploration.

In addition to the conditions listed in the introduction as causing erosion of the skull bone, a number of other erosive conditions may more specifically arise from the middle ear cleft and mastoid area. These include a primary cholesteatoma, cholesteatoma secondary to chronic suppurative otitis media, carcinoma of the middle ear, chronic infections including those due to tuberculosis and fungi leading to osteomyelitis. Nomura, Takemoto and Komatsuzaki (1971) reported a woman with a cyst arising in the mastoid-middle ear region, which contained dark brown, cholesterol-rich fluid, and an isolated area of cuboidal epithelium. They were not certain of its exact origin but it clearly differed from the present case.

Dunkser and McCreary (1971) described a patient with an occipital leptomeningeal cyst. This arose from a childhood occipital skull fracture, which allowed C.S.F. to erode between the inner and outer tables of the skull producing an expanding posterior fossa lesion. This differs from the present case which was not in communication with the C.S.F. pathways. Aneurysmal bone cysts may occasionally occur in the skull, presenting as an expanding space occupying lesion. This has been reported in the occipital bone (Odeku and Mainwaring, 1965), in the temporal bone (Bhende and Kothare, 1950) and in the frontal bone (Burns-Cox and Higgins, 1969). There can, however, be no confusion between the simple unicameral bone cyst in the present case and aneurysmal bone cyst. The latter consists of spongy tissue comprising numerous dilated blood vessels and fibrous tissue and as the cyst is opened, blood wells into the opera- 
tive field (Lichtenstein, 1957; Tillman, Dahlin, Lipscomb and Steward, 1968; Dabska and Buraczewski, 1969).

The appearance in the present case of a simple cyst containing clear, golden yellow proteinacious fluid, with a fibrous wall which was not markedly vascular, corresponds most closely to the descriptions of unicameral bone cysts (Jaffe and Lichtenstein, 1942; Garceau and Gregory, 1954; Aegerter and Kirkpatrick, 1968). This type of cyst usually arises in the metaphysis of a growing long bone, $75 \%$ being in the humerus or femur and males are twice as frequently affected as females. The cyst migrates towards the centre of the shaft as growth continues, probably becoming inactive when skeletal maturation is reached. It has been suggested that it arises as a result of venous obstruction of various cartilagenous or fibrous rests occurring during bone development (Cohen, 1970). It is almost invariably a disease of the long bones but Jacobson (1971) referred to three cases in the ilium. Apart from our present case, it does not appear that there has been any pre- vious report of a simple bone cyst occurring in the calvarium.

\section{REFERENCES}

AEGERTER, E. and KIRKPATRICK, J. A Jr. (1968). Orthopaedic diseases. 3rd edition. W. B. Saunders, Philadelphia, pp. 491-500.

BHENDE, Y. M. and KOTHARE, S. N. (1950). Aneurysmal bone cyst. Indian Medical Gazette, 85, 544-546.

BURNS-COX, C. J. and HIGGINS, A. T. (1969). Aneurysmal bone cyst of the frontal bone. Journal of Bone and Joint Surgery, 51B, 344-345.

COHEN, J. (1970). Etiology of simple bone cyst. Journal of Bone and Joint Surgery, 52A, 1493-1497.

DABSKA, M. and BURACZEWSKI, J. (1969). Aneurysmal bone cyst. Pathology, clinical course and radiologic appearances. Cancer, 23, 371-389.

DAHLIN, D. C. (1967). Bone tumours. Charles C. Thomas, Springfield, Illinois, 112.

DUNKSER, S. B. and McCREARY, H. S. (1971). Leptomeningeal cyst of the posterior fossa. Journal of Neurosurgery, 34, 687-692.

GARCEAU, G. J. and GREGORY, C. F. (1954). Solitary unicameral bone cyst. Journal of Bone and Joint Surgery, 36A, 267-280.
JACKSON, A. and MILTON, G. W. (1960). Osteoclastoma and osteogenic sarcoma occurring in the cranial vault. The British Journal of Radiology, 33, 193-196.

JACOBSON, S.A. (1971). The comparative pathology of the tumours of bone. Charles C. Thomas, Springfield, Illinois, U.S.A., 363-365.

JAFFE, $H$. L. and LICHTENSTEIN, L. (1942). Solitary unicameral bone cyst. Archives of Surgery, 44, 1004-1025.

JOFFE, N. (1965). Calvarial bone defects involving the lambdoid suture in neurofibromatosis. British Journal of Radiology, 38, 23-27.

LICHTENSTEIN, L. (1957). Aneurysmal bone cyst. The Journal of Bone and Joint Surgery, 39A, 873-882.

MUNK, J., PEYSER, E. and GELLEI, B. (1960). Osteoid osteoma of the frontal bone. The British Journal of Radiology, 33, 328-330.

NOMURA, Y., TAKEMOTO, K. and KOMATSUZAKI, A. (1971). The mastoid cyst: report of a case. Laryngoscope, 81, 438-446.

ODEKU, E. L. and MAINWARING, A. R. (1965). Usual aneurysmal bone cyst: a case report. Journal of Neurosurgery, 22, 172-176.

TILLMAN, B. P., DAHLIN, D. C., LIPSCOMB, P. R. and STEWART, J. R. (1968). Aneurysmal bone cyst: an analysis of 95 cases. Proceedings of the Mayo Clinic, 43, 478-495.

TUDWAY, R. C. (1959). Giant cell tumor of bone. British Journal of Radiology, 32, 315-321. 